Hydrogen Corrosion of Plutonium:

Evidence for fast grain-boundary reaction and slower intragrain reaction

C. K. Saw, J. M. Haschke, P. G. Allen, W. McLean II, L. N. Dinh

February 17, 2012

Journal of Nuclear Materials 
This document was prepared as an account of work sponsored by an agency of the United States government. Neither the United States government nor Lawrence Livermore National Security, LLC, nor any of their employees makes any warranty, expressed or implied, or assumes any legal liability or responsibility for the accuracy, completeness, or usefulness of any information, apparatus, product, or process disclosed, or represents that its use would not infringe privately owned rights. Reference herein to any specific commercial product, process, or service by trade name, trademark, manufacturer, or otherwise does not necessarily constitute or imply its endorsement, recommendation, or favoring by the United States government or Lawrence Livermore National Security, LLC. The views and opinions of authors expressed herein do not necessarily state or reflect those of the United States government or Lawrence Livermore National Security, LLC, and shall not be used for advertising or product endorsement purposes. 


\title{
Hydrogen corrosion of plutonium: evidence for fast grain-boundary reaction and slower intragrain reaction
}

\author{
C. K. Saw, J. M. Haschke, P.G. Allen, W. Mclean II and L.N. Dinh \\ Lawrence Livermore National Laboratory, Livermore, CA 94551, USA
}

\begin{abstract}
Infrared pyrometer measurements of reaction-site dimensions and temperature profiles during growth of single hydrogen corrosion sites after exposure of $\mathrm{Pu}$ to $\mathrm{H}_{2}$ are consistent with a multistep reaction sequence for hydride formation. Thermal modeling of the early stage of reaction shows that the predicted temperature increase for $\mathrm{PuH}_{2}$ formation is much larger than observed. Those results and observation of surprisingly low average $\mathrm{H} / \mathrm{Pu}$ ratios imply that initial products are mixtures of $\mathrm{PuH}_{2}$ and metal grains dislodged by grain-boundary hydriding. Such mixtures are formed by fast grain-boundary reaction and slower intragrain reaction as hydrogen corrosion advances into Pu metal. Emissivities of plutonium hydride and oxide-coated metal are reported and differences in reaction rates induced by vertical versus horizontal orientations of the $\mathrm{Pu}$ sample are also described.
\end{abstract}




\section{Introduction}

Corrosion of plutonium by hydrogen is of continuing technological interest because of its relevance to safe handling and storage of the metal and its involvement in reactions that readily transform the metal into dispensible particles [1]. Several investigations that focus on the kinetics and mechanisms of the $\mathrm{Pu}-\mathrm{H}_{2}$ reaction are described in recent reports [2-5].

Hydriding is described as a four-stage process [1, 4, 5]: (a) induction/nucleation, (b) site growth, (c) bulk reaction, and (d) termination. Induction is an eratic time period in which Pu is exposed to $\mathrm{H}_{2}$, but consumption of gas is not detected. The induction period is terminated by nucleation of an autocatalytic hydride site that promotes continuing reaction at that location [1, 6]. During the growth stage, the hydride site increases in size as the hydriding rate increases exponentially over time. The bulk hydriding stage begins when the metal surface is covered by hydride and the reaction proceeds at a rate that depends only on the $\mathrm{H}_{2}$ pressure. The terminal stage is marked by a progressively decreasing rate as one of the reactants is depleted. Unlike the extensively studied bulk and terminal stages, the nucleation and growth stages are not well characterized. The growth stage is of interest because of a rapid exothermic reaction $[1,7]$ occurs in a low thermal conductivity metal [8], a situation that should produce a significant temperature gradient around the reaction site.

The role of the oxide surface layer in altering the corrosion process is discussed in earlier publications [1, 2]. Results show that nucleation of hydriding is inherently suppressed by a $\mathrm{PuO}_{2}$ surface layer because the solubility of hydrogen in the dioxide is much less than the 
concentration required to saturate the metal and to precipitate hydride [2]. Therefore, a hydrogen-transport process other than diffusion of hydrogen through the dioxide is apparently required to form hydride sites beneath a $\mathrm{PuO}_{2}$ layer. In contrast, $\mathrm{Pu}_{2} \mathrm{O}_{3}$, a trivalent oxide that must exist at the oxide-metal interface, catalyzes the $\mathrm{PuH}_{2}$ reaction at a rate comparable to that of the autocatalytic hydride $[1,9]$. Therefore, nucleation of hydriding is promoted by heating $\mathrm{PuO}_{2}$ coated metal in vacuum to form $\mathrm{Pu}_{2} \mathrm{O}_{3}$ or by scribing the $\mathrm{PuO}_{2}$-coated surface to expose $\mathrm{Pu}_{2} \mathrm{O}_{3}$ at the oxide-metal interface [2].

Characterization of the hydriding reaction is difficult because the metal reacts with $\mathrm{H}_{2}$ and generates heat at an unusually rapid rate. However, the transport of heat away from the reaction zone is rather slow due to the low thermal conductivity of Pu. In this study, infrared (IR) pyrometry was used to map the dynamic temperature profiles produced by growth of hydride sites on $\mathrm{PuO}_{2}$-coated $\mathrm{Pu}$. The effect of $\mathrm{Pu}$ surface orientation on heat transfer and hydriding reaction rate was investigated and the emissivities of oxide- and hydride-coated surfaces were measured. A fundamental reassessment of the hydriding process became necessary because independently measured extents of $\mathrm{H}_{2}$ and $\mathrm{Pu}$ consumption during site growth were inconsistent with the conventional view of $\mathrm{PuH}_{2}$ formation during the reaction. Occurrence of an alternative hydriding process is supported by results of heat-transfer thermal modeling of temperatures profiles observed during site growth. 


\section{Experimental methods}

Hydriding experiments were made in an argon-atmosphere glove box using circular (16 mm diameter) coupons cut from a $0.8 \mathrm{~mm}$ thick sheet of polycrystalline delta-phase Ga alloy. The samples were rinsed with ethanol to remove machining residues and dried in air before testing. The thickness of the amber $\mathrm{PuO}_{2}$ surface layer was determined to be about 220nm by ion milling and scanning electron microscopy (Figure 1). During a typical hydriding experiment, the test specimen was mounted in a two-piece aluminum holder fitted with a pair of indium o-ring seals pressed against the perimeter of the Pu sample surface [2]. Access of $\mathrm{H}_{2}$ gas to the $\mathrm{Pu}$ sample during the initial phase of the hydriding process was confined to the visually observable $13 \mathrm{~mm}$ diameter opening in the front aluminum plate. Penetration of the Pu by hydride formation during actual experiments allowed $\mathrm{H}_{2}$ to enter the Ar-filled volume behind the sample and attack the unobservable back side. The mounted sample was placed in a massive Al block that reproducibly positioned the $\mathrm{Pu}$ specimen in an evacuable stainless steel reaction chamber equipped with a turbomolecular pump, type $\mathrm{K}$ thermocouples, calibrated capacitance manometers (MKS), and sapphire windows for pyrometric imaging with an IR camera (Merlin Indigo, FLIR systems, Inc.). The IR camera which had an InSb detector with a cold filter set for photons in the 3-5 $\mu \mathrm{m}$ wavelength range, a resolution of $90 \mu \mathrm{m}$, and a refresh rate of $2 \mathrm{~Hz}$, was positioned $10 \mathrm{~cm}$ from the sample.

During replicate hydriding tests, the extents of hydrogen consumption and the temperature profiles near the reaction sites were measured simultaneously as a function of time. Since meaningful correlation of these results is contingent on confinement of reaction to a single site, 
measurements were facilitated by scribing the oxide surface near the center of each $\mathrm{PuO}_{2}$-coated sample [2]. Reaction preferentially initiated at these sites after rapid pressurization of the evacuated reaction chamber $\left(10^{-4} \mathrm{~Pa}\right)$ with $10.5 \mathrm{mmol}$ of research grade $\mathrm{H}_{2}$ at room temperature (296 $\pm 1 \mathrm{~K}) \cdot \mathrm{H}_{2}$ pressure and corresponding thermal images were recorded with samples in two orientations (vertical and inclined at $45^{\circ}$ ) which are amenable to surface imaging. Particles of hydride formed by spallation of the product felt away from the reaction sites on vertical samples, but accumulated in piles of powder above reaction sites on inclined samples. The consumption of $\mathrm{H}_{2}$ was determined from pressure-time (PVT) measurements and instantaneous reaction rates were derived from $\Delta n$ and $\Delta t$ increments of successive measurements.

The emissivities $(\varepsilon)$ of oxide- and hydride-coated $\mathrm{Pu}$ were determined in vacuum by simultaneous temperature measurements with the IR pyrometer and a thermocouple in contact with the $\mathrm{Pu}$ sample surface. The emissivity of $\mathrm{PuO}_{2}$-coated $\mathrm{Pu}$ was measured at room temperature and with the sample at temperature maintained at $50^{\circ} \mathrm{C}$ by external heating of the reaction chamber. During calibration, the mounted Pu sample was located in the Al holding block that was thermally equilibrated for 15 hours before the measurement and maintained an isothermal condition as the specimen surface was viewed via an access channel. The value of $\varepsilon$ was determined by adjusting the emissivity of the pyrometer software until spectral temperature agreed with the thermocouple reading. In a similar way, $\varepsilon$ of $\mathrm{Pu}_{2} \mathrm{O}_{3}$-coated $\mathrm{Pu}$ was determined after the sample had been heated at $130^{\circ} \mathrm{C}$ in vacuum for 12 hours to reduce the $\mathrm{PuO}_{2}$ surface to $\mathrm{Pu}_{2} \mathrm{O}_{3}$. In order to determine $\varepsilon$ for plutonium hydride, the $\mathrm{Pu}_{2} \mathrm{O}_{3}$-coated sample was exposed to $\mathrm{H}_{2}$ at $50^{\circ} \mathrm{C}$ to produce plutonium hydride $\left(\mathrm{PuH}_{2 \pm \mathrm{x}}\right)$ [1]. At this time, the entire sample was 
covered by a relatively thick, black product layer with a rough texture that might have resulted from spallation of hydride particles. The emissivity of the $\mathrm{PuH}_{2 \pm \mathrm{x}}$ was determined as described for oxide-coated metal. The calibration process was also performed at $32^{\circ} \mathrm{C}$ and $100^{\circ} \mathrm{C}$ with no observable differences in emissivities for the measured samples.

\section{Results}

The measured emissivities of $\mathrm{PuO}_{2}$-coated $\mathrm{Pu}, \mathrm{Pu}_{2} \mathrm{O}_{3}$-coated $\mathrm{Pu}$ and $\mathrm{PuH}_{2 \pm x}$ at normal incidence to the surface are $0.65 \pm 2,0.67 \pm 2$, and $0.92 \pm 2$, respectively. The $\varepsilon$ value for hydride is consistent with properties of this dark and rough surface layer. Since the thickness of the $\mathrm{PuO}_{2}$ layer is only about 220nm, the observed $\varepsilon$ is identified as the emissivity of $\mathrm{PuO}_{2}$-coated $\mathrm{Pu}$, not of $\mathrm{PuO}_{2}$. Although the autoreduction reaction to form $\mathrm{Pu}_{2} \mathrm{O}_{3}$ increases the oxide thickness by 33\%, the measured $\varepsilon$ is representative of $\mathrm{Pu}_{2} \mathrm{O}_{3}$-coated $\mathrm{Pu}$. The observed $\varepsilon$ for $\mathrm{PuO}_{2}$-coated metal lies between the previously reported values of 0.37 for $\mathrm{Pu}$ and 0.85 for $\mathrm{PuO}_{2}[10-11]$ and implies that the results reported here are reliable.

A chronological set of thermal images for a representative test with vertically mounted coupon is shown in Figure 2. The dot in the middle of the zero-time image marks the location of the scratch that was added to expose the $\mathrm{Pu}_{2} \mathrm{O}_{3} / \mathrm{Pu}$ interface. Nucleation of hydriding at the site was followed by continuing growth over time. The appearance of additional reaction sites after 4 minutes shows that hydriding inherently nucleates due to the presence of impurities, defects, or other features that promote nucleation [2]. During the first 6 minutes of reaction, the 
temperature at the initial hydriding site increased by 5-6K. Growth of the initial site resulted in formation of a several-millimeter diameter site and attainment of the maximum $\Delta \mathrm{T}(\sim 60 \mathrm{~K})$ after 17 minutes. Reaction of the $\mathrm{H}_{2}$ was complete about 19 minutes.

A sequence of images obtained with an inclined sample as shown in Figure 3. Except for the sample orientation, the experimental conditions and procedures of multiple tests were identical to those for vertical samples. Comparison of images for replicate tests with samples in two orientations shows that the number of secondary nucleation sites on inclined samples after 4 minutes consistently exceeded the corresponding number for vertical samples by a factor of 4-5. The total time for consumption of the $\mathrm{H}_{2}$ charge was about 12 minutes. The maximum $\Delta \mathrm{T}$ ( 105K) is almost twice that observed with vertical samples.

Hydrogen inventories and hydriding rates for vertical and inclined samples are presented as functions of time in Figures 4(a) and (b), respectively. There was no induction time. As shown in both sets of graphs, the difference between the reaction profiles and rates are small during the first 3 minutes of reaction. The diameters of the initial hydride spots shown in Figures 2 (vertical) and 3 (inclined) are graphed as a function of time in Figure 5(a) and (b), respectively. The results show that the diameters of the growing hydride sites increased at constant rates during the first 6 minutes of reaction and that the rates of expansion during this time period were comparable for both orientations. Although the measured rate of $\mathrm{H}_{2}$ consumption increased exponentially during the initial 6-7 minutes of reaction (see Figure 4(b)), an essentially constant area-normalized rate of $15 \pm 4 \mu \mathrm{mol} \mathrm{cm} \mathrm{cs}^{-2}$ was obtained prior to any observed hydride spallation (first four minutes of reaction). 
Efforts to determine the stoichiometry of hydride products during the course of reaction yielded mixed results. The extents of $\mathrm{H}_{2}$ and Pu consumption during the initial minutes were derived from PVT data and from hemispherical volumes defined by reaction-site radii obtained by pyrometric imaging, respectively. These data give $\mathrm{H} / \mathrm{Pu}$ ratios much lower than 2 after 1-2 minutes of reaction, but the results are very uncertain because changes in $\mathrm{H}_{2}$ pressure could not be reliably measured near zero time. Results based on extents of $\mathrm{H}_{2}$ consumption calculated by integration of linear $\log \mathrm{dH}_{2} / \mathrm{dt}$ curves for vertical and inclined samples also give average $\mathrm{H} / \mathrm{Pu}$ ratios less than 2 for products formed during the initial three minutes of reaction. However, the terminal $\mathrm{H} / \mathrm{Pu}$ ratios based on the total consumption of $\mathrm{H}_{2}$ and the mass of Pu lost during reaction are always near 3.0. An unexpected, but consistently observed, result for both sample orientations is seen by comparing the images for 17 and 20 minutes in Figure 2. The reaction of $\mathrm{H}_{2}$ was $90-95 \%$ complete after 17 minutes, but the size of the hole in the sample increased by about three-fold as the remaining hydrogen was consumed during the subsequent three-minute period.

\section{Thermal modeling}

Properties of the $\mathrm{Pu}-\mathrm{H}_{2}$ reaction during the initial stage of site growth have been characterized by modeling of the thermal profiles induced by exothermic hydriding. Although thorough computational modeling of $\Delta T$ values observed during hydriding (Figures 2 and 3) is both difficult and beyond the scope of this study, calculations of thermal profiles for the first few minutes of a test is tractable because reaction is confined to one hydride site located at the center 
of the sample. Since the Pu-H phase diagram [1, 7, 12-14] shows coexistence of hydrogensaturated $\mathrm{Pu}$ and $\mathrm{PuH}_{2 \pm \mathrm{x}}$ with $\mathrm{x} \sim 0$ at $298 \mathrm{~K}$, corrosion is assumed to proceeed with formation of $\mathrm{PuH}_{2}$. As indicated by the absence of detectable particle spallation during the first few minutes of reaction, the $\mathrm{PuH}_{2}$ product is taken to proceed isotropically (see Figure 6) and to remain on the corrosion site in the thermal modeling.

If the thermal properties of the adherent product are assumed to be similar to those of Pu metal, transport of heat away from the initial site in the center of a circular coupon is most easily described in cylindrical coordinates [15]:

$$
\frac{\partial T}{\partial t}=\frac{K}{c_{p}^{o} \rho}\left(\frac{\partial^{2} T}{\partial r^{2}}+\frac{1}{r} \frac{\partial T}{\partial r}+\frac{\partial^{2} T}{\partial z^{2}}\right)
$$

The parameters $r$ and $z$ are the radial and vertical coordinates as defined in Figure 6. $K(\sim 6.74$ $\left.\mathrm{W} \mathrm{m} \mathrm{K}^{-1}\right), c_{p}^{0}\left(\sim 158 \mathrm{~J} \mathrm{~K}^{-1} \mathrm{~kg}^{-1}\right)$, and $\rho\left(15840 \mathrm{~kg} \mathrm{~m}^{-3}\right)$ are the thermal conductivity, specific heat, and density of $\delta$-Pu, respectively [8]. The specific heat for $\mathrm{PuH}_{2}$ is $\sim 186 \mathrm{~J} \mathrm{~K}^{-1} \mathrm{~kg}^{-1}$ [7]. In the absence of thermal conductivity data for $\mathrm{PuH}_{2}\left(\rho=10400 \mathrm{~kg} \mathrm{~m}^{-3}\right), K$ for thin hydride product layer is assumed equal to that of Pu. Equation (1) is a partial differential equation (PDE) with first order in time and second order in $r$ and $z$. This equation is relatively insensitive to the initial size and geometry of the heat source (the scribed area near the center of the coupon at time $t=0$ ) and assumes no angular dependence for the heat flow. Heat transfer during hydriding of $\mathrm{Pu}$ is treated as a problem with an expanding heat source (advancing reaction front) in a finite-length cylinder (circular sample of known thickness). Although the finite cylinder problem with an expanding heat source is extremely difficult to solve analytically [15], a solution has been 
obtained using a finite difference approach to differentiation (numerical approximation) with the commercial software COMSOL [16].

A unique solution to equation (1) is obtained if initial condition and boundary conditions are specified. $\Delta T$ values observed during the first few minutes of reaction are small (Figures 2 and 3) and radiative heat transfer is negligible relative to convective and conductive heat transfers. Since thermal conductivities of $\mathrm{Ar}, \mathrm{H}_{2}, \mathrm{Pu}$, In, and $\mathrm{Al}$ at room temperature are roughly 0.016 , 0.168, 6.74, 82, and $237 \mathrm{~W} \cdot \mathrm{m}^{-1} \cdot \mathrm{K}^{-1}$, respectively [17], and since Pu samples were mounted in an Al holder with In o-ring seals, convective transfer is small (a few percent of the total) and can be ignored. Therefore, thermal insulation is assumed at all boundaries except at the sample edge where conductive transfer exists due to intimate contact with the aluminum sample holder via the indium o-ring seals.

Mathematical definitions of initial and boundary conditions follow. At time $t=0$, the initial condition is $T(t=0, r, z)=T_{o}$ where $T_{o}$ is the initial experimental temperature $(296 \pm 1 \mathrm{~K})$. The boundary conditions for $z$ are thermal insulation everywhere except at the reaction front where it is:

$$
K \frac{\delta T}{\delta z_{\text {|reaction front }}}=F_{o}
$$

$F_{o}$ is the heat flux from the reaction front in the $z$ direction. In a similar way, the boundary condition for $r$ at the reaction front is: 


$$
K \frac{\delta T}{\delta r_{\text {|reaction front }}}=F_{o}
$$

The value of $F_{o}\left(41.3 \mathrm{~kJ} \mathrm{~m}^{-2} \mathrm{~s}^{-1}\right)$ is determined by the product of the moles of Pu in a monolayer per unit surface area of a face centered cubic $\left(a_{o}=0.463 \mathrm{~nm}\right)$ metal $\left(9.33 \times 10^{18}\right.$ atoms $\mathrm{m}^{-2}$ in a monolayer or $15.5 \mu \mathrm{mol} \mathrm{m}{ }^{-2}$ per monolayer), the heat of formation of $\mathrm{PuH}_{2}\left(-164.4 \mathrm{~kJ} \mathrm{~mol}^{-1}\right)$, and the velocity of the reaction front. As defined in Figure 5(a), the reaction front advances at a rate of $3.75 \mu \mathrm{m} \mathrm{s}^{-1}$ (16199 monolayers of Pu per second) into the vertical sample.

The heat flux from the Pu sample to the $\mathrm{Al}$ sample holder is described by equation 4a.

$$
K \frac{\delta T}{\delta r_{\text {coupon edge }}}=H_{s c}\left(T_{\text {ext }}-T\right)
$$

Although the value of $H_{s c}$, the interfacial thermal conductance of the Pu/In/Al junction at the edge of the sample is not available, the $H_{s c}$ value for the Fe/Al junction $\left(45 \mathrm{~kW} \mathrm{~m}^{-2} \mathrm{~K}^{-1}\right)$ is reported [18]. The thermal conductivity of Fe $\left(80 \mathrm{~W} \mathrm{~m}^{-1} \mathrm{~K}^{-1}\right)$ and $\mathrm{In}\left(82 \mathrm{~W} \mathrm{~m}^{-1} \mathrm{~K}^{-1}\right)$ exceeds that of Pu (6. $74 \mathrm{~W} \mathrm{~m}^{-1} \mathrm{~K}^{-1}$ ) by more than an order of magnitude. Therefore, the interfacial thermal conductance of the $\mathrm{Pu} / \mathrm{In} / \mathrm{Al}$ junction is dominated by the thermal resistance of Pu. Application of a ten-fold reduction factor to $H_{s c}$ for the Fe/Al junction gives an $H_{s c}$ of $3.0-4.5 \mathrm{~kW} \mathrm{~m}^{-2} \mathrm{~K}^{-1}$ for the $\mathrm{Pu} / \mathrm{In} / \mathrm{Al}$ junction. Calculations show that the temperature profile changes by only a few percent as $H_{s c}$ is varied over this range. The external temperature measured at the $\mathrm{Al}$ sample holder remained constant (equal to $T_{o}$ ) for several minutes after the start of hydriding. 
The adequacy of equation 4(a) has been verified by setting the boundary condition with the sample edge fixed at $T_{o}$. This condition is equivalent to having a good thermal contact with a heat sink at $T_{o}$ as described by equation 4(b).

$T\left(t, z, r_{\text {coupon edge }}\right)=T_{o}$

Values of calculated $\Delta T$ for the first few minutes of reaction via equations 4(a) and (b) differ by only a fraction of a degree.

Equation (1) has been solved numerically in COMSOL using the initial and boundary conditions specified above and heat generation by an expanding source illustrated in Figure 5 by equation 5 .

$r_{H}=0.07+0.00375 \mathrm{t}$

The source radius $r_{H}$ has units of $\mathrm{mm}$ and defines the location of the reaction front as it advances into the $\mathrm{Pu}$ metal, forming stoichiometric $\mathrm{PuH}_{2}$. Time, $t$, in equation 5 has units of second. Equation 5 is linked to the heat-transfer equation by coupling the deformed geometry interface with the heat conduction interface in COMSOL. The thermal modeling result for a vertical sample after a 200 sec reaction period (Figure 7) corresponds with the pyrometer image for 3.3 minutes in Figure 2. The calculated maximum $\Delta T$ of the $\mathrm{PuH}_{2}$ product area is approximately $20 \mathrm{~K}$, a result that is 8 times larger than the $2.5 \mathrm{~K}$ increase shown by pyrometric measurements. Similar results are obtained for the inclined sample shown in Figure 3. By comparing Figures 2 and 8 , agreement between the observed and calculated $\Delta T$ is obtained if the amount of heat released during the initial 3.3 minutes of reaction is reduced by $85 \%$. 


\section{Discussion}

The observed difference in maximum $\Delta \mathrm{T}$ values for vertical $(\sim 60 \mathrm{~K})$ and inclined $(\sim 105 \mathrm{~K})$ samples is consistent with properties of $\mathrm{PuH}_{2 \pm x}$, a product that spalls as small particles due to stress created by formation of a low density solid on a higher-density solid. Spalled particles accumulate as a pile of hydride powder if the sample mounting position is inclined (or horizontal), but fall away and carry a sizable fraction of the heat if the sample is oriented vertically. In addition to this physical effect, consideration must be given to the stoichiometry of the spalled particles. Reference to the $\mathrm{Pu}-\mathrm{H}$ phase diagram [1] shows that $\mathrm{PuH}_{2 \pm \mathrm{x}}$ is an extended solid solution with a temperature-dependent lower phase boundary and a maximum composition of $\mathrm{PuH}_{3}$. At $800^{\circ} \mathrm{C}$, the hydride coexisting with hydrogen-saturated liquid $\mathrm{Pu}$ is $\mathrm{PuH}_{1.75}$ and the equilibrium $\mathrm{H}_{2}$ pressure is about $50 \mathrm{kPa}$. $\mathrm{PuH}_{2}$ is an ideal composition within the $\mathrm{PuH}_{2 \pm x}$ continuum with a modest $(-164 \mathrm{~kJ} / \mathrm{mol})$ enthalpy of formation and a heat capacity of $43.5 \mathrm{Jmol}^{-}$ ${ }^{1} \mathrm{~K}^{-1}$ [7]. If $\mathrm{PuH}_{2}$ formed at the reaction front during hydriding, the microscale adiabatic temperature increase ( $\Delta H_{f}^{o} / C_{p}^{o}$ ) would be extreme. The temperature of spalling hydride particles is undoubtedly elevated and the $\mathrm{H} / \mathrm{Pu}$ ratios are probably less than 2 . Observation verifies that particles of hydride continue to react after the spallation [19] and attain higher compositions, up to $\mathrm{PuH}_{3}\left(\Delta H_{f}^{o}=-211 \mathrm{~kJ} / \mathrm{mol}\right)$ as they cool to room temperature in $\mathrm{H}_{2}$ [7]. In large measure, the $\Delta T$ values of vertical samples are low relative to those of inclined samples because the heat product from continuing reaction of spalled particles with $\mathrm{H}_{2}$ does not contribute to heating up the vertical samples. 
The pyrometer images of vertical (Figure 2) and inclined (Figure 3) samples after 4 minutes show the presence of secondary hydride sites in addition to the initial large site. As noted above, data from multiple tests show that the number of secondary sites on inclined samples substantially and consistently exceeds the number on vertical samples. That smaller number of sites on the vertical samples reflects the relatively sluggish nucleation behavior of the $\mathrm{PuO}_{2}$ coated metal source [2]. Appearance of additional secondary sites on inclined samples after about 3 minutes coincides with the point at which ejection of hydride particles from the reaction site is observed. Since the resolution $(90 \mu \mathrm{m})$ of the IR camera precludes the detection of smaller particles, spallation at earlier points in time was either negligible or produced very small particles. Appearance of secondary sites shortly after onset of spallation on the inclined sample suggests that continuing nucleation is promoted by the deposition of hot spalled-hydride particles, which continue to exothermically react with $\mathrm{H}_{2}$, onto nearby $\mathrm{PuO}_{2}$ landing sites, converting them to catalytic $\mathrm{Pu}_{2} \mathrm{O}_{3}$.

Modeling of the thermal profiles confirms that the $\mathrm{PuH}_{2}$ reaction does not proceed as anticipated. The difference in calculated and observed $\Delta T$ values after 3.3 minutes of reaction is large and consideration must be given to possible sources of the discrepancy. The possibility of an inaccurate $\Delta H_{f}$ for $\mathrm{PuH}_{2}$ is readily dismissed because of the accepted value is based on results of solution calorimetry and equilibrium pressure measurements that are in excellent agreement [7]. A large error in $\Delta T$ is also very unlikely because the pyrometer-thermocouple calibrations were made and verified under carefully controlled isothermal conditions. Another possibility is that the assumed growth geometry of the hydride spot, employed in the modeling, is invalid. The extent of heat generated over time is strongly dependent on the corrosion site geometry. The reaction clearly advances into the metal. However, the assumption that hydride growth is 
isotropic and produces a hemispherical corrosion site cannot be confirmed or rejected on the basis of pyrometric images in Figures 2 and 3. The remaining possible source of error is the assumption that hydriding at room temperature proceeds with instantaneous formation of $\mathrm{PuH}_{2}$ at the reaction front as implied by the equilibrium phase diagram [1]. The possibility of forming a corrosion product with a low $\mathrm{H} / \mathrm{Pu}$ ratio merits consideration. The only known reaction other than $\mathrm{PuH}_{2}$ formation is dissolution of the hydrogen in the metal, a slow process that produces negligible heat [12].

Although hydride corrosion sites might not be exactly hemispherical, they were observed to be three dimensional and contained substantially more metal than required to generate the measured $\Delta T$ values by $\mathrm{PuH}_{2}$ formation. Since the reaction consistently formed hydride, the initial product obtained during site growth might be a mixture of $\mathrm{Pu}$ and $\mathrm{PuH}_{2}$ in a ratio that produced the requisite amount of heat for the observed $\Delta T$. The multi-step mechanism based on this concept is initiated by the presence of $\mathrm{Pu}_{2} \mathrm{O}_{3}$ or another catalytic surface site that promotes rapid dissociation of absorbed $\mathrm{H}_{2}$ and transport of product $\mathrm{H}$ to the oxide-metal interface. A sharp hydride-metal boundary does not form because hydrogen is simultaneously dispensed into the metal by two kinetically controlled processes. Rapid movement of hydrogen into the bulk metal by diffusion along grain boundaries is countered by sorption on inter-granular surfaces at concentrations that exceed the low solubility of hydrogen in $\mathrm{Pu}$ at $25^{\circ} \mathrm{C}$ [12]. Growth of hydride results in coverage of grains with low-density $\mathrm{PuH}_{2}$, a product that creates inter-granular stress and causes grains to separate from the bulk metal. 
Experimental observations during the initial minutes of reaction on the vertical sample are limited, but agree with the proposed mechanism. After $3.3 \mathrm{~min}$, the reaction site reached a radius of about $0.8 \mathrm{~mm}$ and involved several hundred metal grains. The extent of $\mathrm{H}_{2}$ consumption during that time remained below the detection limit of the pressure transducer, but could be estimated by extrapolation and integration of the rate-time data in Figure 4(b). The maximum measured $\Delta T$ was only $2.5 \mathrm{~K}$. According to the proposed concept, rapid enlargement of the site occurs as grains are dislodged by a limited extent of $\mathrm{PuH}_{2}$ formation. The anticipated $\Delta T$ is much less than calculated for a 0.8-mm-radius dihydride site because the extents of $\mathrm{PuH}_{2}$ formation and heat generation are small. The mole fraction of unreacted metal in the dislodged grains is large compared to that of surface hydride and a low average $\mathrm{H} / \mathrm{Pu}$ ratio is expected. Results presented here are consistent with entry into a dynamic process after initiation of hydriding. Development of the reaction over time is accompanied by continuing grain-boundary penetration of hydrogen into the metal and formation of hydride on inter-granular surfaces. Growth of $\mathrm{PuH}_{2}$ on surfaces adjacent to dislodged grains is facile and results in their separation at the rate characteristic of reaction-front advancement. The dislodged grains tend to fall away from sites on vertical samples, but accumulate in a pile of powder above sites on inclined and horizontal samples. In both cases, these grains are coated with catalytic hydride and continue to react rapidly with $\mathrm{H}_{2}$. The average $\mathrm{H} / \mathrm{Pu}$ ratio based on site size and PVT results progressively increases over time as the fraction of $\mathrm{PuH}_{2}$ in the separated product increases. That ratio continues to increase and ultimately approaches 3 as metal grains are converted to hydride and continue to react with $\mathrm{H}_{2}$.

Separation and continuing reaction of metal grains presumably continues during the bulk stage of reaction. The constant temperature-independent rate reported for bulk hydriding $\left(120 \mu \mathrm{mol} \mathrm{cm}{ }^{-2}\right.$ 
$\left.\mathrm{s}^{-1}\right)$ [1] is close to a factor of ten larger than the area-normalized rate observed during the initial four minutes of site growth. An increase in the rate is expected as hydriding proceeds because the effective surface area of Pu per unit geometric area increases as metal grains accumulate in the reaction zone. At some point, the rate at which the reactive area increases by grain dislodgement equals the rate at which that area is decreased by hydride formation, and a steady state reaction rate is reached. The observation of a lower area-normalized hydriding rate for site growth than for bulk reaction is consistent with the proposed mechanism because the maximum effective area of Pu was clearly not reached during the initial four minutes of reaction.

Although development of the reaction site on an inclined sample is difficult to monitor because of the unfavorable viewing angle and the accumulation of powdered product, such is not the case for vertical samples. An unexpected observation (Figure 2) is the absence of a corrosion hole in the sample until 14-17 min into the test, a result that seems to contradict the assumption of isotropic site growth. Penetration of the metal was expected after about 3 min and appearance of a visible hole was anticipated after 6 min. At that point in time, a circular high-temperature spot is clearly present at the center of a somewhat cooler zone that defines the corrosion site. That result is consistent with retention of dislodged metal at the site and its continuing reaction to form $\mathrm{PuH}_{2}$ plus heat. The product at the center was most likely held in place for an extended period due to compressive forces generated by thermal expansion and formation of low-density $\mathrm{PuH}_{2}$ between separated grains. Attainment of the final site configuration after 17-20 min was apparently delayed by slow reaction of hydrogen from grain boundaries of the metal and by the effects of cooling to ambient temperature. The corrosion hole observed after 20 min was stable and its dimensions were consistent with those anticipated for isotropic reaction. 
In addition to accounting for experimental results of this study, the description of site growth outlined above is supported by observation of site formation and growth during reaction of uranium with hydrogen. Except for a relatively sluggish nucleation process and a slow diffusion-controlled transport of hydrogen in autocatalytic $\mathrm{UH}_{3}$, the hydrogen corrosion reactions of $\mathrm{U}$ and $\mathrm{Pu}$ are remarkably similar and apparently proceed via the same series of sequential steps. A hot-stage microscope study of hydride formation on polished polycrystalline $U$ at the elevated temperatures $\left(130-150^{\circ} \mathrm{C}\right)$ required to promote nucleation [20] shows that sites identified as hydride were formed in grain boundaries and crystallographic dislocations within minutes after exposure of the metal to hydrogen at $133 \mathrm{kPa}$. After a period of about $30 \mathrm{~min}$ in which no detectable change in spot size was detected, some of the sites began to grow at a constant rate and the number of growing sites progressively increased over time. Behavior is similar to that of $\mathrm{Pu}$, but is more obvious because sluggish reaction of $\mathrm{U}$ resolves the initial stage of site development into three well-defined steps: (1) initial formation of sites by grain-boundary diffusion of hydrogen into the metal, (2) nucleation of autocatalytic hydriding at grain-boundary surfaces in some sites, and (3) constant-rate growth of those hydride sites as hydrogen advanced into the metal along grain boundaries and inter-granular reaction separated grains from the bulk metal. Although not investigated during the study with the hot-stage microscope, continuing reaction of dislodged grains produces a mound of $\mathrm{UH}_{3}$ powder at the site over time. During reaction of $\mathrm{Pu}$, the three-step sequence is compressed into a three-minute time period. 


\section{Conclusions}

Data obtained from simultaneous PVT and pyrometric measurements provide a unique view of the initial stage of the $\mathrm{Pu}-\mathrm{H}_{2}$ reaction. The measurement were possible because experimental methods developed in prior studies consistently result in nucleation of a single hydride site at a desired location on the surface of oxide-coated Pu. Observed temperature increases and product stoichiometries are much lower than expected for transformation of metal in the reaction site to $\mathrm{PuH}_{2}$. Evaluation of experimental observations leads to the conclusion that products formed during initial minutes of reaction at hydride sites are mixtures of $\mathrm{Pu}$ metal and $\mathrm{PuH}_{2}$.

Contrary to expectation, results show that hydriding does not proceed with instantaneous formation of $\mathrm{PuH}_{2}$ at a sharply defined reaction interface. Observations suggest that hydride is formed via a multi-step process in an extended reaction zone. Hydride formation on oxidereacted metal initiates at a catalytic site that dissociates $\mathrm{H}_{2}$ and transport $\mathrm{H}$ to the oxide-metal interface, but occurs only after hydrogen diffuses along grain boundaries and reaction nucleates on inter-granular surfaces. The initial hydride site contains $\mathrm{PuH}_{2}$-coated $\mathrm{Pu}$ grains dislodged by formation of low-density hydride in the grain boundaries. Production of heat is limited and the average $\mathrm{H} / \mathrm{Pu}$ ratio of the product is low. Further reaction is expected to result in formation of an extended reaction zone in which Pu grains are continuously dislodged and progressively hydrided over time.

The utility of thermal measurements and modeling in kinetic measurements is amply demonstrated. In this study, neither dimensional nor pressure measurements were adequate. 
Both the value of IR pyrometry and its potential for use in investigation of rapid gas-solid reactions are evident.

\section{Acknowledgement}

This work performed under the auspices of the U.S. Department of Energy by Lawrence Livermore National Laboratory under Contract DE-AC52-07NA27344.

\section{References}

[1] J. M. Haschke, J. L. Stakebake, in The Chemistry of the Actinide and Transuranium Elements, vol. 5, L. R. Morss, N. M. Edelstein, J. Fuger, Springer, 2006, pp. 3199-3272.

[2] L.N. Dinh, J.M. Haschke, C.K. Saw, P.G. Allen, W. McLean II, J. of Nuclear Materials, 408 (2011) 171-175.

[3] J.M. Haschke, T.J. Allen, and L.A. Morales, Los Alamos Science, 26 (2000) 253-273.

[4] G.W. McGillivray, J.P. Knowles, I.M. Findlay, M.J. Dawes, J. of Nuclear Materials, 412 (2011) 35-40.

[5] G.W. McGillivray, J.P. Knowles, I.M. Findlay, M.J. Dawes, J. of Nuclear Materials, 385 (2009) 212-215.

[6] K. Balasubramanian, T. E. Felter, T. Anklam, T. W. Trelenberg, W. McLean II, J. Alloys Compds. 444-445 (2007) 447-452. 
[7] H. E. Flotow, J. M. Haschke, S. Yamauchi, The Chemical Thermodynamics of Actinide Elements and Compounds, part 9, F. L. Oetting, Ed., International Atomic Energy Agency, Vienna, 1984.

[8] O. J. Wick, Ed., Plutonium Handbook, American Nuclear Society, 1980.

[9] J. M. Haschke, T. H. Allen, J. Alloys Comp. 320 (2001) 58-71.

[10] R.H. Karlsson, J. of Nuclear Materials 19 (1966) 79-80.

[11] W.N. Seery, J. of Nuclear Materials 25 (1968) 64-68.

[12] T. H. Allen, The Solubility of Hydrogen in Plutonium in the Temperature range 475 to 826 degrees Centigrade, Thesis, University of Colorado at Denver, Denver, CO, 1991.

[13] J. M. Haschke, US Department of Energy Report, RFP-3099, Rocky Flats Plant, Golden, CO, 1981.

[14] R. N. R. Mulford, G. E. Sturdy, J. Amer. Chem. Soc., 77 (1955) 3449.

[15] H. S. Carslaw and J. C. Jaeger, “Conduction of Heat in Solids”, $2^{\text {nd }}$ edition, Clarendon Press, Oxford, 2001.

[16] COMSOL Multiphysics version 4.2a, by COMSOL Inc., Stockhom, Sweden.

[17] Handbook of Chemistry and physics, 59 $9^{\text {th }}$ edition, CRC Press, Florida, 1979.

[18] These values can be found from the following online educational source:

http://www.kxcad.net/SolidWorks/COSMOSWorks_online_help/analysisbackground/thermalana lysis/thermal_contact_resistance.htm 
[19] J. M. Haschke, The Synthesis of Lanthanide and Actinide Compounds, G. Meyer and L. R. Morss, Eds., Kluwer, 1991, pp 1-53.

[20] J. Bloch, F. Simca, M. Kroup, A. Stern, D. Shmariahu, M.H. Mintz, J. Less-Common. Metals 103 (1984) 163-171.

\section{Figure captions}

Figure (1): SEM image of an oxide-coated Pu sample after sectioning and ion milling. The oxide layer is measured to be about $220 \mathrm{~nm}$. The texture of $\mathrm{Pu}$ in the milled region was altered by interaction with the $\mathrm{Ga}$ ion beam at $30 \mathrm{kV}$ and is not indicative of metal properties. The microscope used for this work was a Quanta 3D FEG model from FEI.

Figure (2): Sequential thermal profiles of a vertical Pu sample during reaction with $\mathrm{H}_{2}$.

Figure (3): Sequential thermal profiles of an inclined Pu sample during reaction with $\mathrm{H}_{2}$.

Figure (4): Hydrogen consumption data derived from PVT data measured for vertical and inclined Pu samples during reaction with $\mathrm{H}_{2}$. Figure (4a) shows the shows the time dependence inventories of $\mathrm{H}_{2}$. Figure (4b) shows the time dependence of the reaction rate of $\mathrm{H}_{2}$.

Figure (5): The time dependence of the initial site radii for vertical (5a) and inclined (5b) Pu samples during reaction with $\mathrm{H}_{2}$.

Figure (6): Orientation of the cylindrical Pu sample and the corrosion site in cylindrical coordinates.

Figure (7): Results of thermal modeling calculation for reaction of the vertical Pu sample with $\mathrm{H}_{2}$. Surface and internal temperatures calculated after $3.3 \mathrm{~min}$ of reaction are indicated by the accompanying color scale. 
Figure(8): Results of thermal modeling calculation for reaction of the inclined Pu sample with $\mathrm{H}_{2}$. Surface and internal temperatures calculated after $3.3 \mathrm{~min}$ of reaction are indicated by the accompanying color scale. 


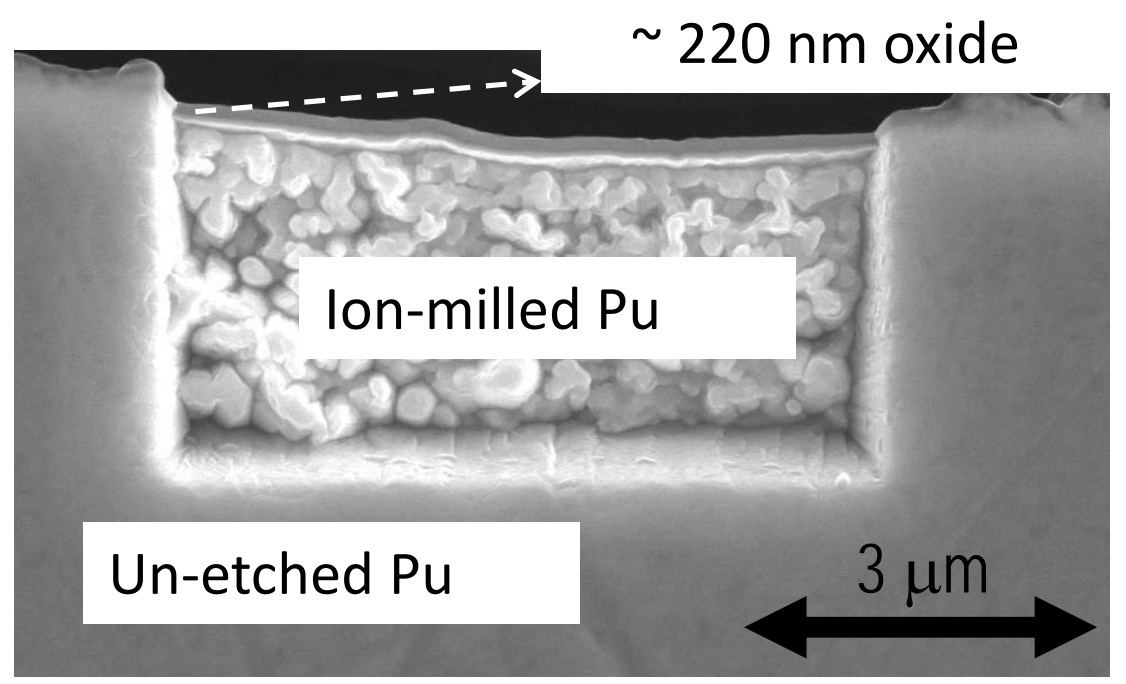

Fig. 1 

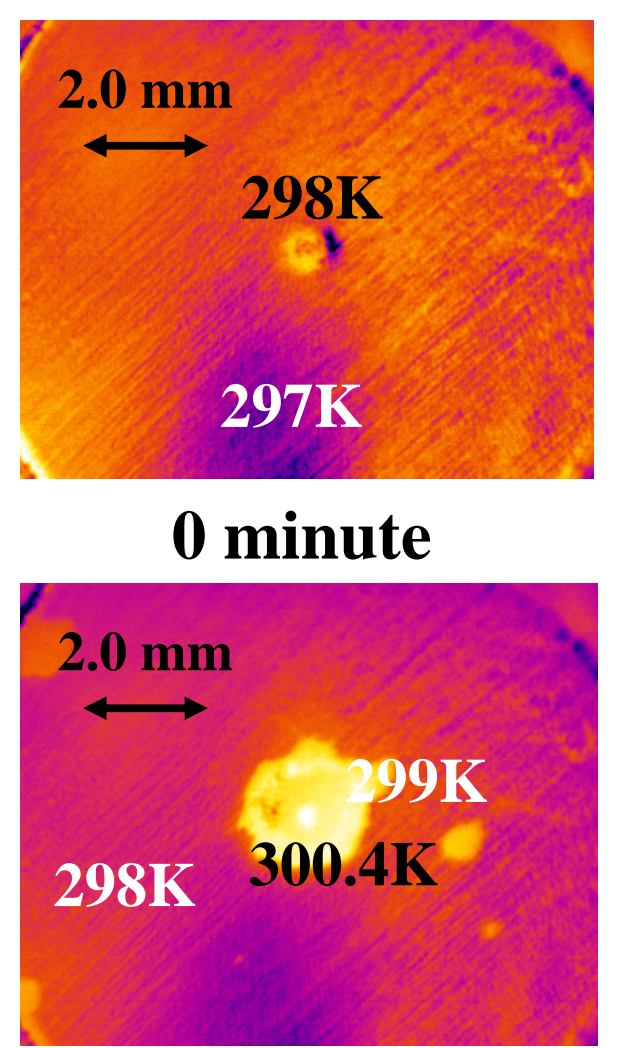

4 minutes

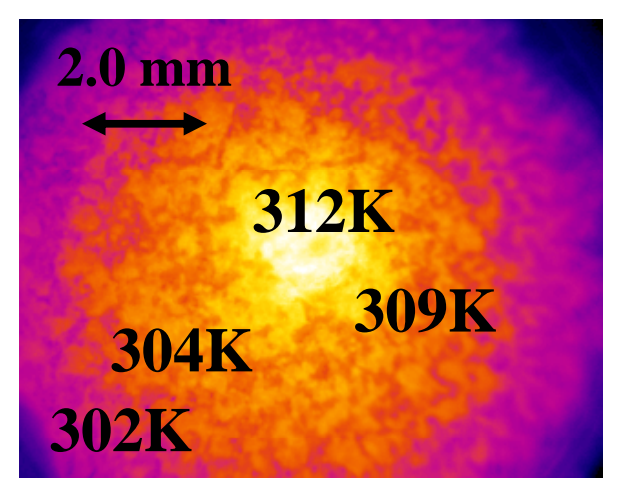

14 minutes

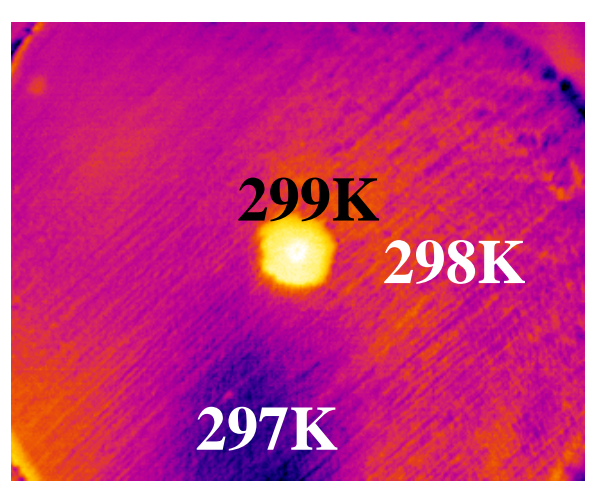

2 minutes

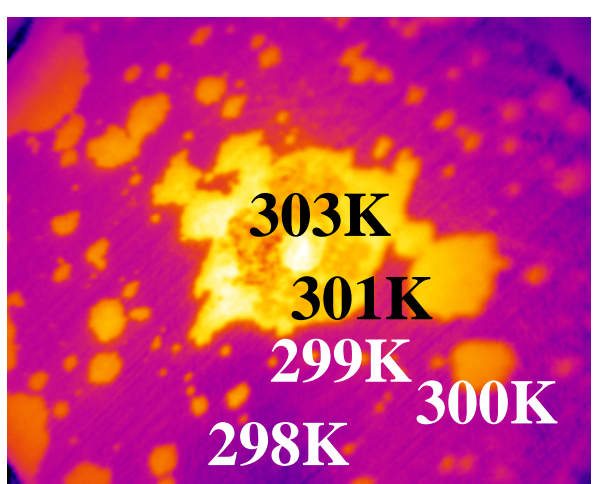

6 minutes

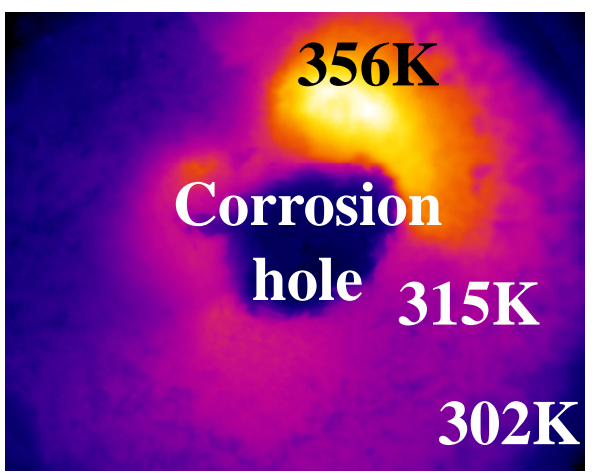

17 minutes

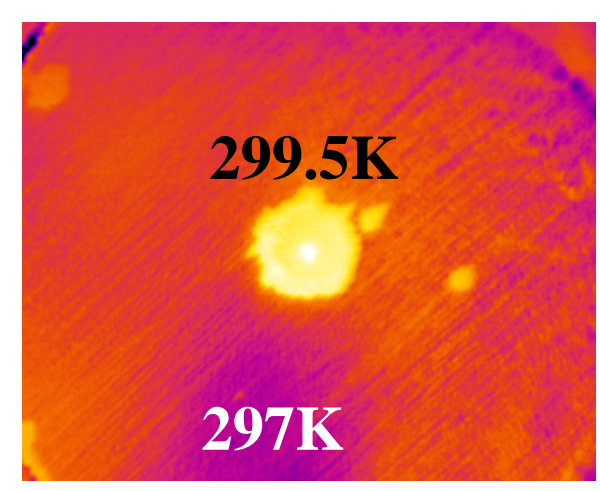

3.3 minutes

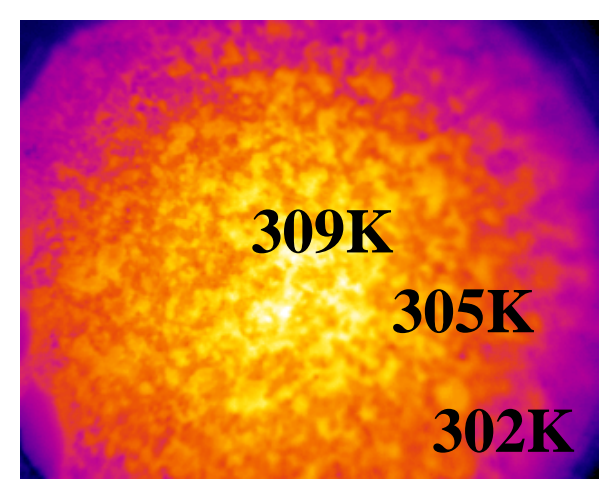

10 minutes

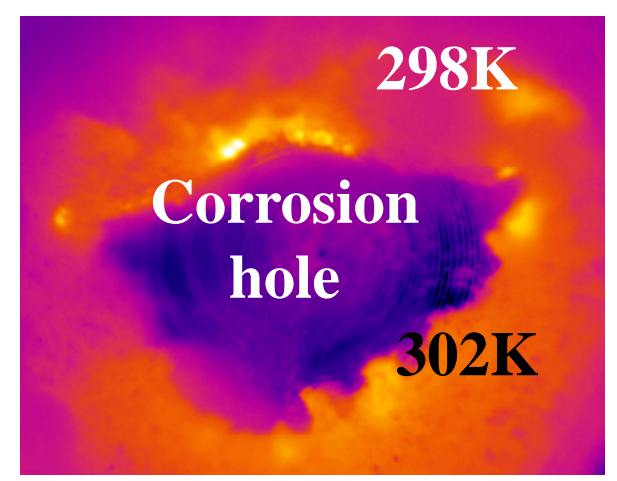

20 minutes 


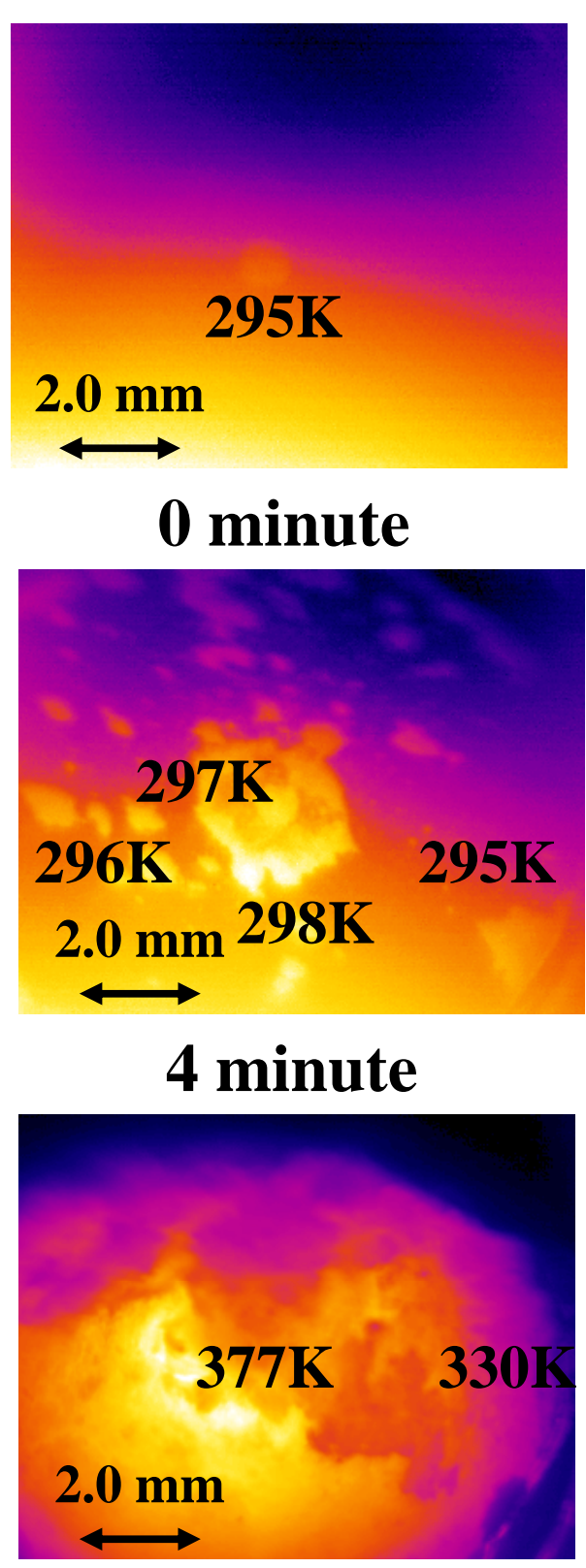

10 minute
295K 296K

2 minute

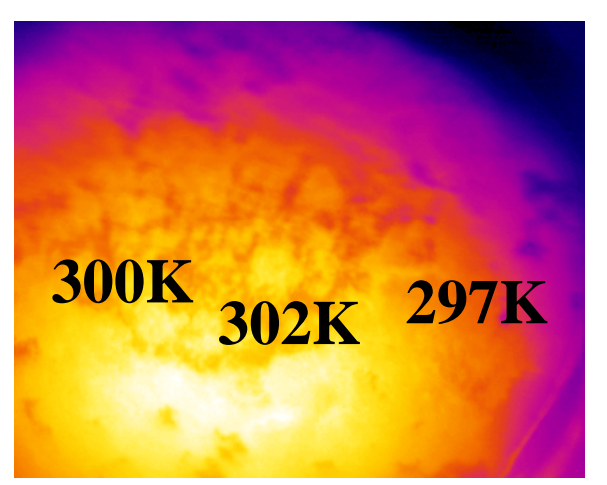

6 minute

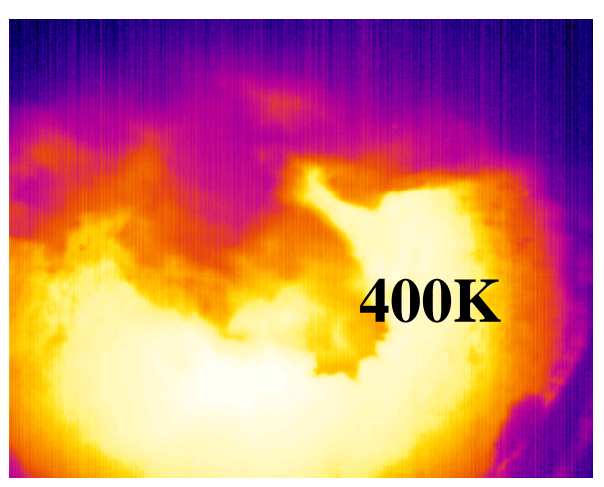

11 minute

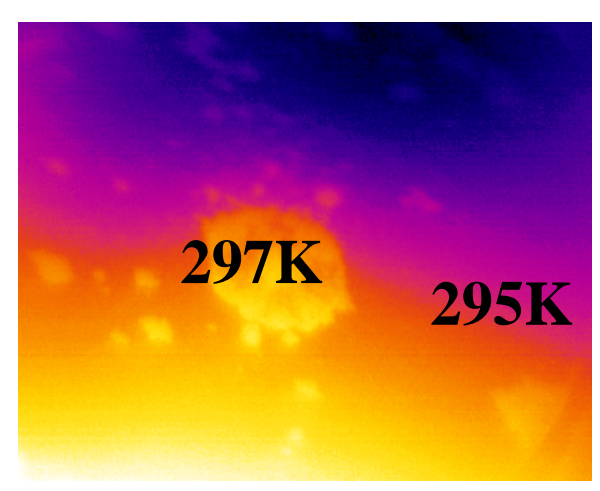

3.3 minute

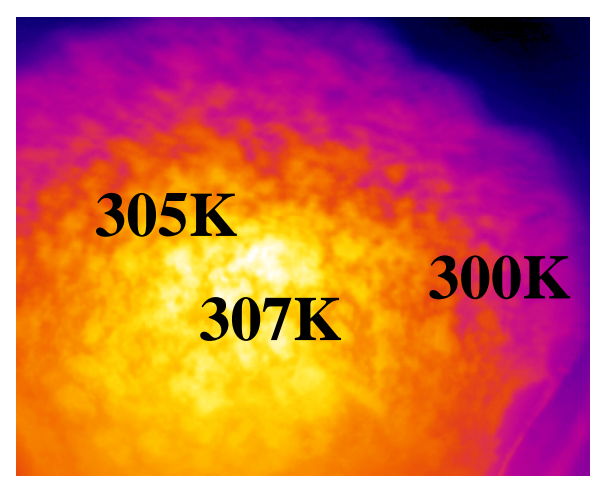

8 minute

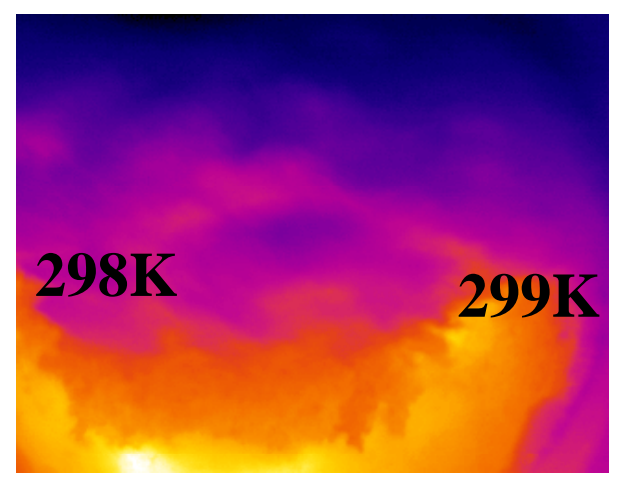

12 minute

Fig. 3 

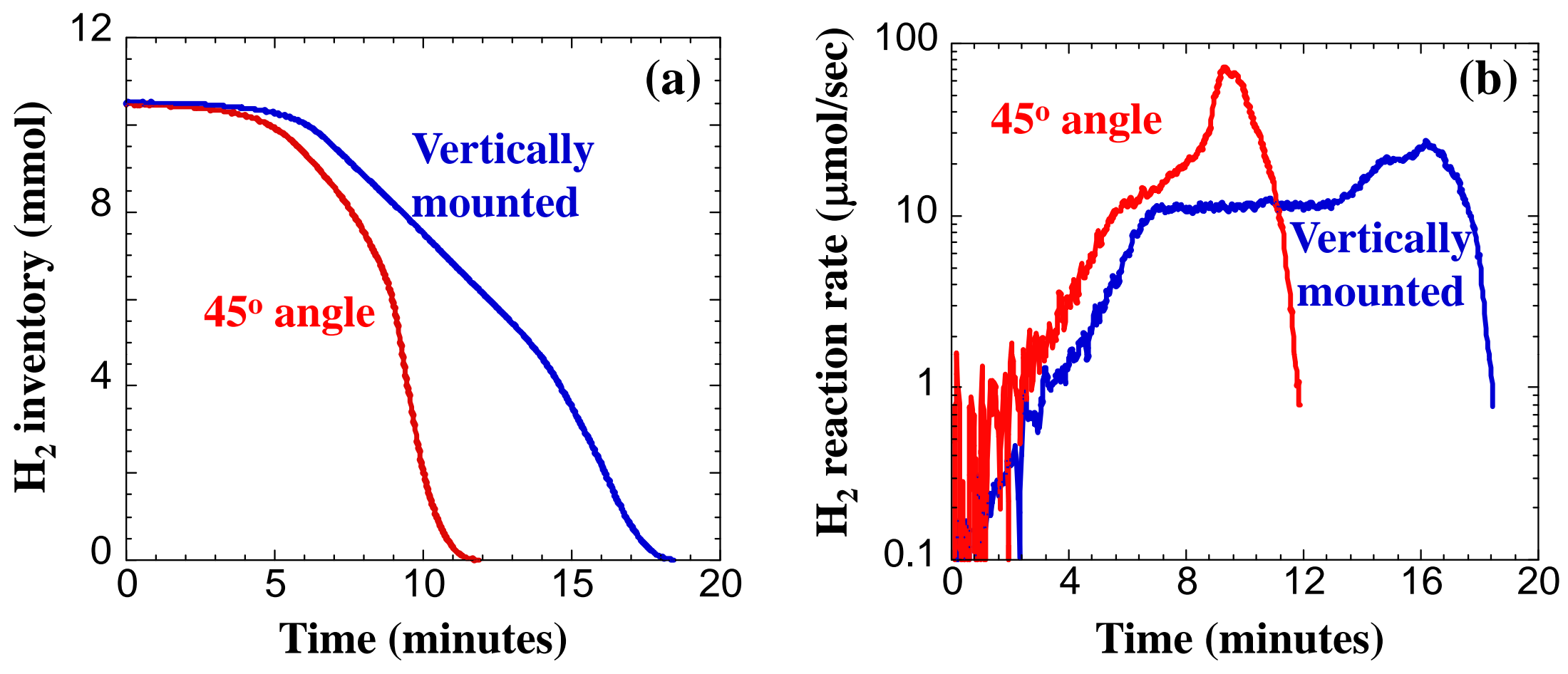

Fig. 4 

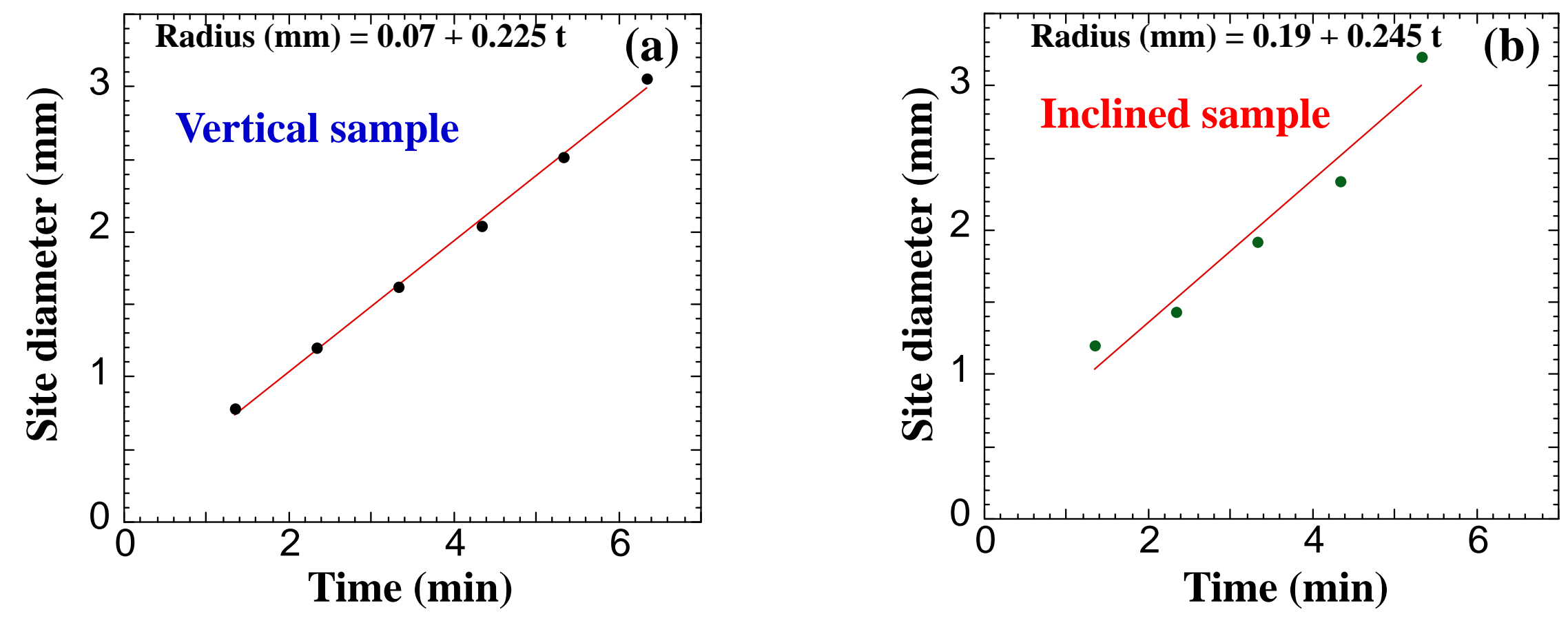

Fig. 5 


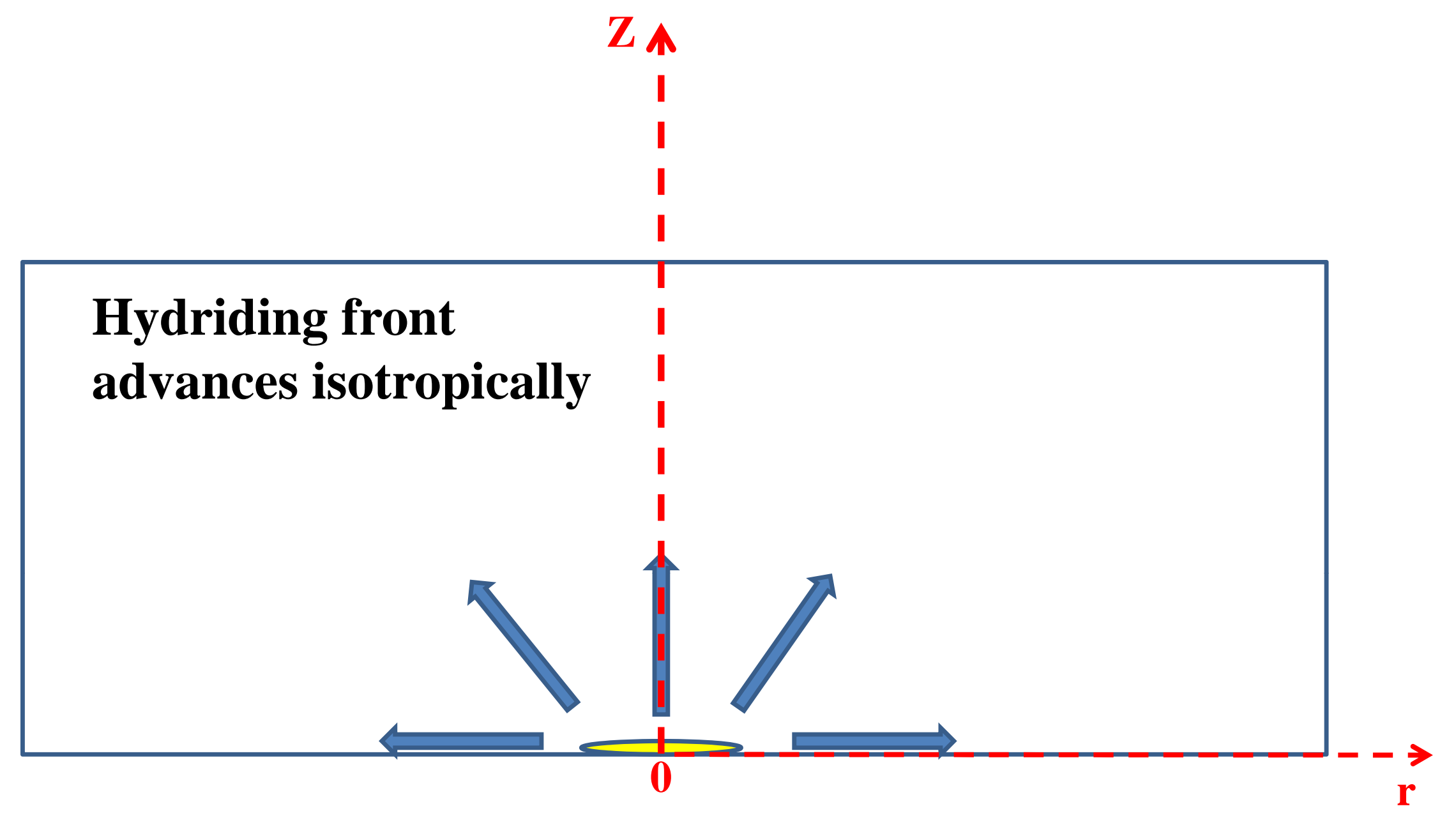

Scribed area

Fig. 6 


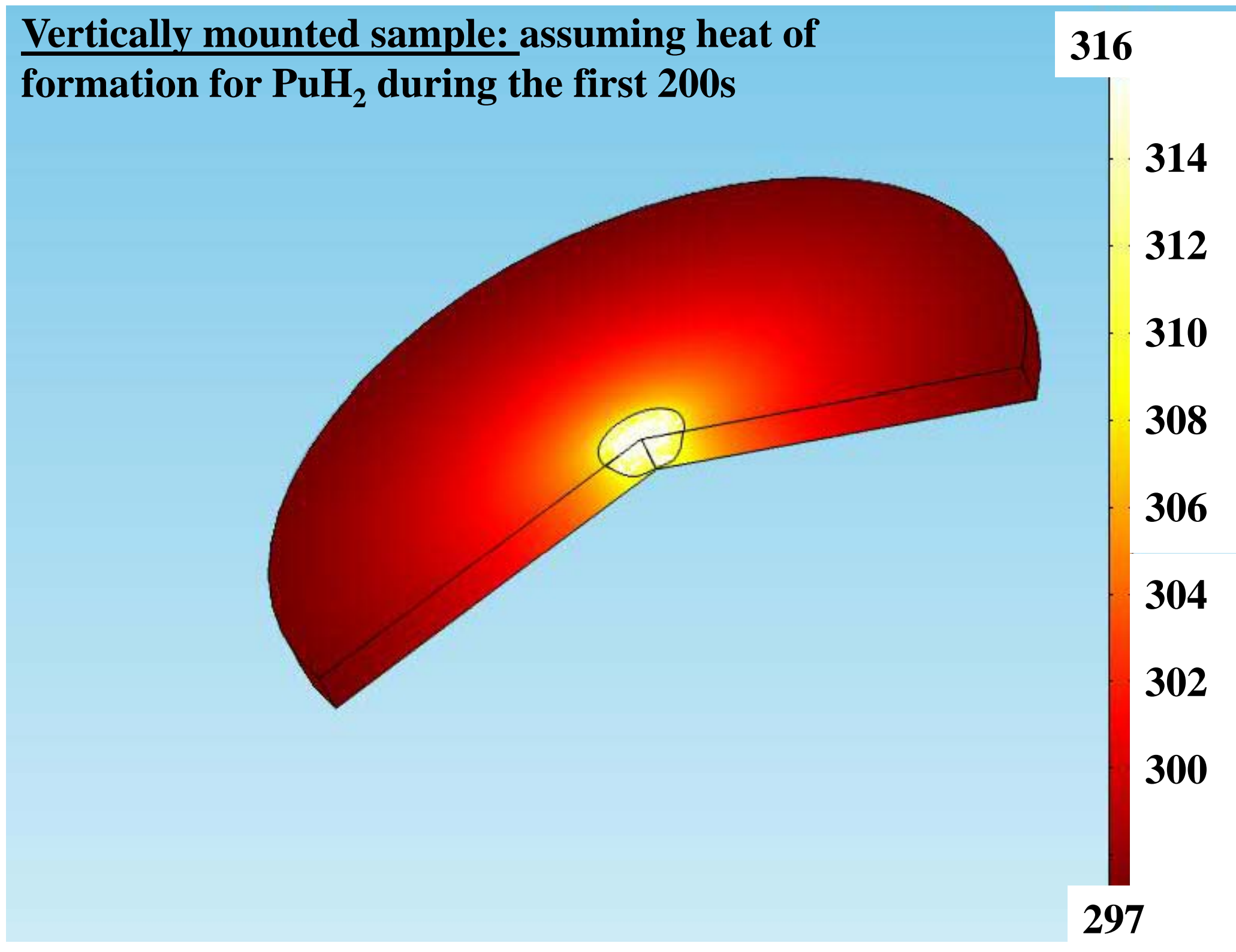

Fig. 7 


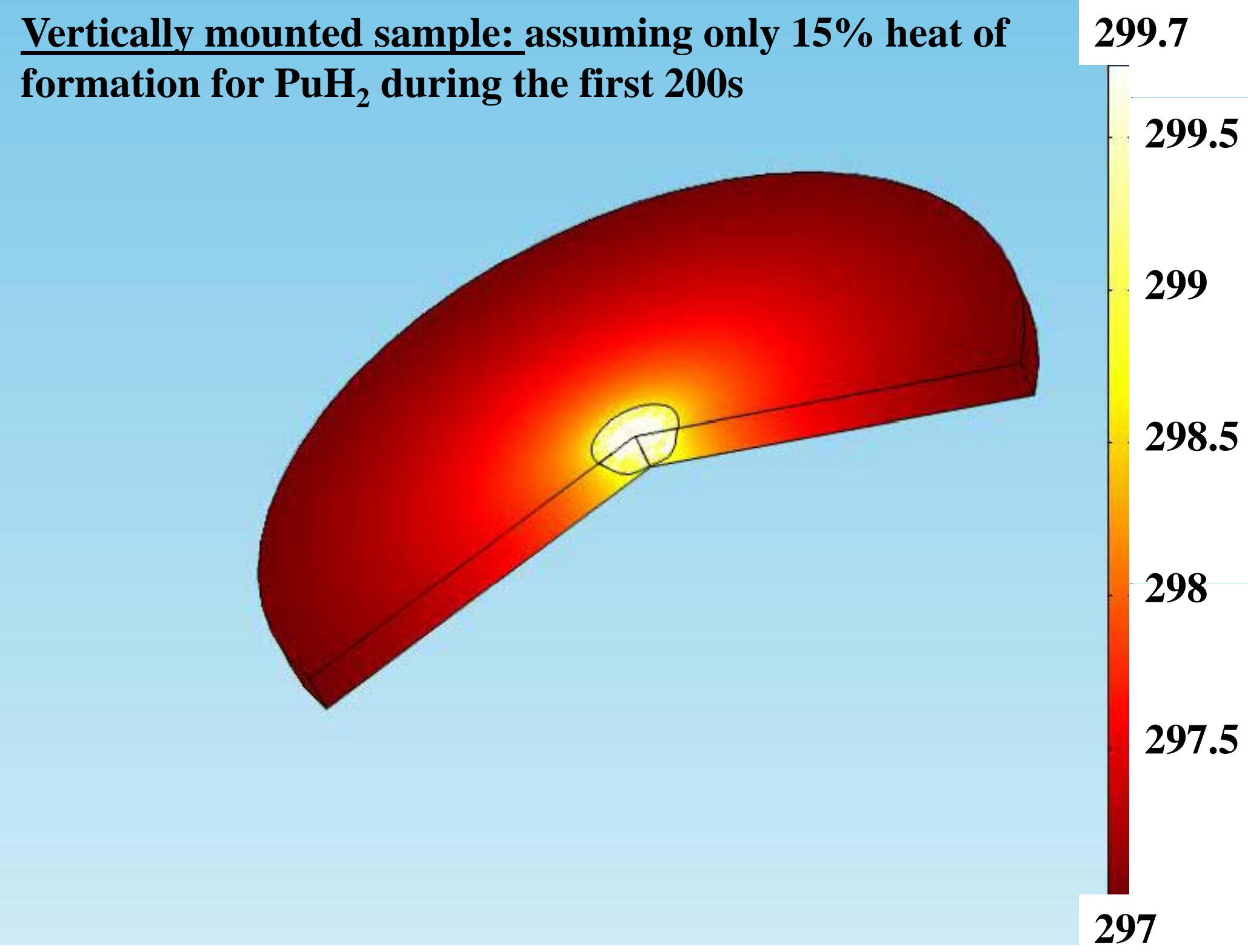

Fig. 8 